\title{
Effect of Farm Broadcast Programmes on Gain in Knowledge of Farmers on Rice Production Technology in Andhra Pradesh
}

\author{
M. V. Krishnaji ${ }^{1 *}$, T. Gopi Krishna ${ }^{2}$ and N. Deborah Messiana ${ }^{1}$ \\ ${ }^{1}$ Krishi Vigyan Kendra, Undi, West Godavari district, Andhra Pradesh, India \\ ${ }^{2}$ Director of Extension, Acharya N.G.Ranga Agricultural University, Lam, Guntur \\ Andhra Pradesh, India \\ *Corresponding author
}

\section{A B S T R A C T}

\section{Keywords}

Farm broadcast programmes, Gain in Knowledge,

Knowledge test, Rice production technology, Experimental group, Control group, Television, Televiewing farmers

\section{Article Info}

Accepted: 12 December 2020 Available Online: 10 January 2021
The study on effect of farm broadcast programmes on gain in knowledge of farmers on "Rice production technology" was conducted during the year 2018 19 as a part of Ph. D research work. The study was conducted in four districts viz., West Godavari, Srikakulam, Kurnool and Guntur districts of Andhra Pradesh with a sample size of 240 in experimental group and 60 in control group. Knowledge test on rice production technology was constructed with 43 items having item difficulty index ranging from 20 to $80 \%$ and item discrimination index ranging from 0.2 to 0.8 . The respondents in experimental group were exposed to farm broadcast programme and collected knowledge levels before and after exposure. The knowledge levels of control group respondents also collected without exposure to farm broadcast programme. Knowledge gap among the respondents was studied with mean knowledge difference scores of tele viewing farmers. The mean knowledge scores immediately after exposure were 20.18 in experimental group and 13.67 in the control group. The gain in knowledge score was 7.12 in experimental group and 1.04 in control group. The computed ' $t$ ' value was found to be positive and significant at 0.01 level of probability, indicating that there was a positive and significant difference between knowledge levels before exposure and after exposure to farm broadcast programme viz., rice production technology.

\section{Introduction}

In India, two third of the population depending upon agriculture sector and one fourth of countries GDP is contributed by agriculture. But, it is very upsetting to note that, the insufficient coverage of agriculture information in media including print and electronic which is even less than two percent. This is probably because of the nonlucrative nature of farm information to the media organizers. It is not only nonglamorous information, but also nonprofitable to them. Presently Television has become the most prominent medium in India for the delivery of information, news, 
entertainment etc., with a revenue of Rs. 66,000 Crores. It represents around 59.5 per cent of the total media industry. The TV industry continues to have scope for further growth as television penetration in India is still at approximately 66.00 percent of total households. As per an industry reports, total TV households in India accounted for 183 million out of 286 million households by 2018.

The DTH platform is also growing with number of DTH households reaching a figure of 67.83 million in 2018. India, today, has a large broadcasting and distribution network, comprising 875 television channels, around 6000 multi system operators, approximately 60,000 LCOs, 7 DTH / Satellite TV operators and few IPTV service providers (TRAI, 2018).

The Broadcast Audience Research Council Survey report, 2018 revealed that, there is a $2.00 \%$ increase of television penetration from 2016 to 2018 (64.00\% to $66.00 \%), 7.5 \%$ jump in television owning homes (183 million to 197 million) and $7.2 \%$ jump in television viewing individuals (780 million to 836 million). These facts show the strength of television as an important medium of mass communication in India. (www.barcindia.co.in).

In the present context of increasing importance of television for communication of farm information, what is expected is that an appropriate content, process, structure and system that are to be pragmatically developed. For that purpose the present study was taken up to know the impact of farm television programmes on knowledge gain of the farmers of Andhra Pradesh. The study was conducted experimentally during the year 2018 - 19 in four districts covering sixteen mandals of Andhra Pradesh, where Rice is the major crop.

\section{Materials and Methods}

Experimental research design was followed to know the impact of farm broadcast programme on "Rice production technology".

Experimental design is defined by Singh (1998) as "Simply a sequence of steps (taken ahead of time), which permit the objective analysis of objective data in a way that a definite cause and effect relationship can be inferred between the independent variable and the dependent variable". The research study primarily aimed to assess the impact of important extension technique namely farm broadcast programme, hence, the 'Before and after' experimental design with control group was used in this research. In this design before and after exposure (experimental areas) as well as control area were selected and the knowledge gain is measured in both the areas for an identical time period before the treatment. The treatment was then introduced into the test area only, and the knowledge gain was measured in both for an identical time period after the introduction of the treatment. The treatment effect was determined by subtracting the change in the knowledge gain in the control area from the change in the knowledge gain in test area.

\section{Sampling procedure}

The state of Andhra Pradesh is selected purposively as the researcher hails from this state and well acquainted with the regional language i.e., Telugu. Four districts out of 13 districts namely West Godavari, Kurnool, Guntur and Srikakulam were selected randomly. After listing all the mandals of selected districts, two mandals from each district were chosen randomly, there by a total of eight mandals were selected randomly. After listing all the villages, two villages from each of the selected mandal was chosen randomly and it comprise a total of sixteen 
villages. For conducting experimental study control group is very much essential. For this purpose four villages were selected (one village from each selected district) randomly. After listing out the total number of farmers who were in possession of TV sets (whether possessing land or not), 15 farmers from each of the selected village were chosen by simple random sampling method, there by the total sample size become 240. And Fifteen farmers from four control group villages were selected randomly, there by the total control group sample size become 60 .

\section{Construction of knowledge test}

Knowledge Test on "Rice production technology" was constructed with 43 items having item difficulty index ranging from 20 to $80 \%$ and item discrimination index ranging from 0.2 to 0.8. Data on knowledge items were collected from 240 (Experimental group) and 60 (Control group) televiewing farmers before and after viewing the farm broadcast programme separately. Knowledge scores of televiewing farmers were calculated for rice production technology and the difference of scores were also worked out, the possible range of gain in knowledge was between 0 and 43. Knowledge gap among the televiewing farmers on rice production technology was tested for its significance with the help of paired ' $t$ ' test and values were computed with table values at 0.01 and 0.05 level of probability.

To test the significance of difference of mean values of scores obtained at before exposure stage and immediately after exposure stage in each of the farm broadcast programme, paired t- test was employed. The following formula was used for calculating the value of ' $t$ '.

$$
\mathrm{t}=\frac{\bar{d}}{S E_{(\bar{d})}}=\frac{(\bar{X}-\bar{Y})}{S E_{\bar{d}}}
$$

Where

$$
\begin{array}{lll}
\bar{d} & = & \bar{X}-\bar{Y} \\
\mathrm{X} & = & \text { mean of pre-exposure scores } \\
\mathrm{Y} & = & \text { mean of post exposure scores } \\
& \bar{d} \quad=\quad \frac{(d i-\bar{d})^{2}}{n(n-1)} \\
\mathrm{di}= & \text { difference of core for ith individual } \\
\mathrm{n}= & \text { sample size }
\end{array}
$$

The significance of calculated ' $t$ ' value was tested by referring to the fisher and Yates.

Depending on the total knowledge scores of individual televiewing farmers, the level of knowledge on rice production technology were tabulated using mean and standard deviation.

\begin{tabular}{|c|l|c|}
\hline S. No. & \multicolumn{1}{|c|}{ Gain in Knowledge } & Range \\
\hline 1. & Low & $<$ Mean - SD \\
\hline 2. & Medium & Mean \pm SD \\
\hline 3. & High & $>$ Mean + SD \\
\hline
\end{tabular}

\section{Results and Discussion}

\section{Effect of Farm Broadcast Programmes on Experimental Group in Relation to Gain in Knowledge about Rice Production Technology}

The knowledge levels of the experimental group before and after exposure were taken to find out the gain in knowledge of televiewing farmers. The distribution of televiewing farmers according to their gain in knowledge on rice production technology was analyzed and the results were presented in Table 1.

The results furnished in Table 1. and Figure 1. indicated that in experimental group, before exposure to farm broadcast programme on rice production technology, the highest per cent fall under low knowledge (50.83\%) category followed by those coming under medium $(34.15 \%)$ and high $(15.00 \%)$ knowledge categories. Further, it is also observed after exposure to farm broadcast 
programme i.e rice production technology to experimental group, the highest $(54.16 \%)$ per cent of respondents fell under medium knowledge, followed by those coming under high $(26.67 \%)$ and low knowledge $(19.17 \%)$ categories.

From the findings of Table 1, it could observed that there was a significant increase in medium and high level knowledge categories after exposure to farm broadcast programme viz. rice production technology. It indicates that the intervening variable known as farm broadcast programme had shown significant effect on increasing the knowledge levels of farmers. The possible reason might be, television is a powerful audio-visual medium, which will enhance seeing and hearing senses for better understanding of subject being broadcasted.

Further, it was also observed that farmers were satisfied with overall visual quality, sound quality, subject coverage and sequencing of the programme. Because, more than eighty per cent $(80.83 \%)$ of the farmers fall under medium and high knowledge categories after exposure to farm broadcast programme. Only 19.17 per cent of the farmers fall under low knowledge category, because it is natural trend that every society is having some amount of laggards, who were reluctant to change.

By this, it could be concluded that the intervening variable viz., farm broadcast programme showed significant positive effect with regard to gain in knowledge of farmers with regard to rice production technology. The extension agencies should keep in mind that there is scope for improving medium knowledge level of farmers to high knowledge level by encouraging them to see the farm broadcast programmes with full concentration and without any dilution. And with regard to programme producers, they should broadcast need based and timely programmes, as all the farmers selected were having some amount of rice cultivation, which clearly indicates the importance of need based information.

The result was in conformity with the findings Mishra and Sharma (1967), Kaur (1970), Sadamate and Sinha (1974), Knight and Singh (1975), Chandrakandan (1982), Dey (1986), Mrutyunjayam (1987), Vikram (2000) and Reddy (2002) and they pointed out that video presentation had produced remarkable impact on gain in knowledge of the rice production technology disseminated.

\section{Effect of Farm Broadcast Programmes on Control Group in Relation to Gain in Knowledge about Rice Production Technology}

From the Table 2. and Figure. 2. it was clear that before exposure, majority $(51.66 \%)$ of the televiewing farmers of control group were in the category of low knowledge with regard to rice production technology followed by 33.34 per cent with medium knowledge and 15.00 per cent with high knowledge. Whereas, after exposure, it could be observed that there was a slight increase in medium (35.00\%) and high (16.67\%) categories and a slight reduction in low knowledge (48.33\%) categories with regard to rice production.

It could be inferred from the Table 2, that there is slight gain in knowledge after exposure to rice production technology without intervening variable viz. farm broadcast programme. This might be due to extraneous profile characteristics which were not considered under this study.

Similar observation made by Shankaraiah and Singh (1967), Singh and Verma (1987), Cherian and Chandra (1989), Kumari and Roy (1988), Jeyakumar and Manoharan (1999). 
Table.1 Distribution of experimental group according to their level of knowledge before and after exposure to farm broadcast programme on rice production technology $(n=240)$

\begin{tabular}{|c|l|c|c|c|c|}
\hline \multirow{2}{*}{ S. No. } & \multicolumn{2}{|c|}{ Category } & \multicolumn{2}{c|}{ Before Exposure } & \multicolumn{2}{c|}{ After Exposure } \\
\cline { 3 - 6 } & & Frequency & $\begin{array}{c}\text { Percentag } \\
\text { e }\end{array}$ & $\begin{array}{c}\text { Frequenc } \\
\mathbf{y}\end{array}$ & $\begin{array}{c}\text { Percentag } \\
\text { e }\end{array}$ \\
\hline 1. & Low (<6.76) & 122 & 50.83 & 46 & 19.17 \\
\hline 2. & Medium (6.75 to 19.82) & 82 & 34.17 & 130 & 54.16 \\
\hline 3. & High (> 19.82) & 36 & 15.00 & 64 & 26.67 \\
\hline \multicolumn{2}{|r|}{ Total: } & $\mathbf{2 4 0}$ & $\mathbf{1 0 0 . 0 0}$ & $\mathbf{2 4 0}$ & $\mathbf{1 0 0 . 0 0}$ \\
\hline
\end{tabular}

Table.2 Distribution of control group according to the level of knowledge before and after exposure to farm broadcast programme on rice production technology $(n=60)$

\begin{tabular}{|c|l|c|c|c|c|}
\hline \multirow{2}{*}{ S. No. } & \multicolumn{2}{|c|}{ Category } & \multicolumn{2}{|c|}{ Before Exposure } & \multicolumn{2}{c|}{ After Exposure } \\
\cline { 3 - 6 } & & Frequency & Percentage & Frequency & Percentage \\
\hline 1. & Low $(<6.79)$ & 31 & 51.66 & 29 & 48.33 \\
\hline 2. & Medium (6.79 to 18.47) & 20 & 33.34 & 21 & 35.00 \\
\hline 3. & High (> 18.47) & 9 & 15.00 & 10 & 16.67 \\
\hline \multicolumn{2}{|c|}{ Total: } & $\mathbf{6 0}$ & $\mathbf{1 0 0 . 0 0}$ & $\mathbf{6 0}$ & $\mathbf{1 0 0 . 0 0}$ \\
\hline
\end{tabular}

Table.3 Difference in mean gain in knowledge of experimental and control group farmers after exposure to farm broadcast programme on rice production technology

\begin{tabular}{|c|c|c|c|c|c|}
\hline \multirow[t]{2}{*}{ S. No. } & \multirow[t]{2}{*}{ Category } & \multicolumn{2}{|c|}{ Mean Score } & \multirow{2}{*}{$\begin{array}{c}\text { Differenc } \\
\mathrm{e}\end{array}$} & \multirow[t]{2}{*}{ t-value } \\
\hline & & $\begin{array}{c}\text { Before } \\
\text { Exposure }\end{array}$ & $\begin{array}{c}\text { After } \\
\text { Exposure }\end{array}$ & & \\
\hline 1. & $\begin{array}{l}\text { Experimental } \\
(\mathrm{n}=240)\end{array}$ & 13.06 & 20.18 & 7.12 & $35.25 * *$ \\
\hline 2. & Control group $(n=60)$ & 12.63 & 13.67 & 1.04 & $5.23 * *$ \\
\hline
\end{tabular}

** Significant at 0.01 level of probability

Table.4 Mean difference in the scores of knowledge levels between experimental and control group farmers on rice production technology

\begin{tabular}{|c|l|c|c|}
\hline S. No. & \multicolumn{1}{|c|}{ Category } & Mean Knowledge score & 't' value \\
\hline 1. & Experimental group $(n=240)$ & 7.12 & $14.62 * *$ \\
\hline 2. & Control group $(n=60)$ & 1.04 & \\
\hline
\end{tabular}

** Significant at $1 \%$ level 
Fig.1 Distribution of experimental group according to their level of knowledge before and after exposure to farm broadcast programme on rice production technology

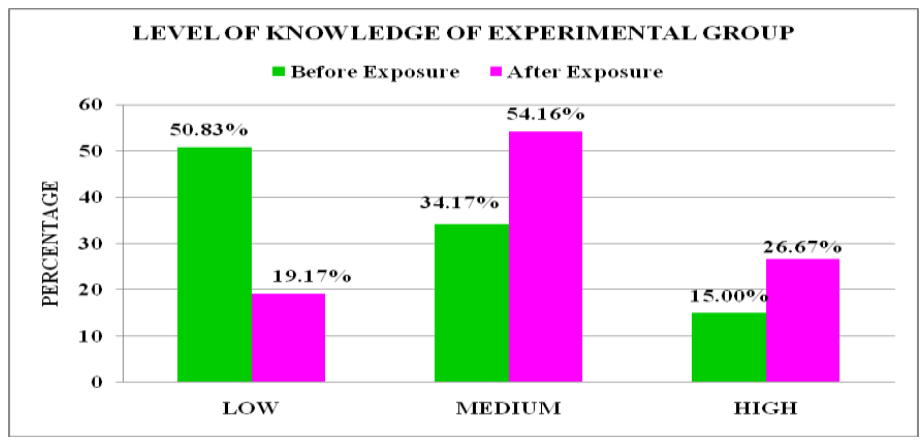

Fig.2 Distribution of control group according to their level of knowledge before and after exposure to farm broadcast programme on rice production technology

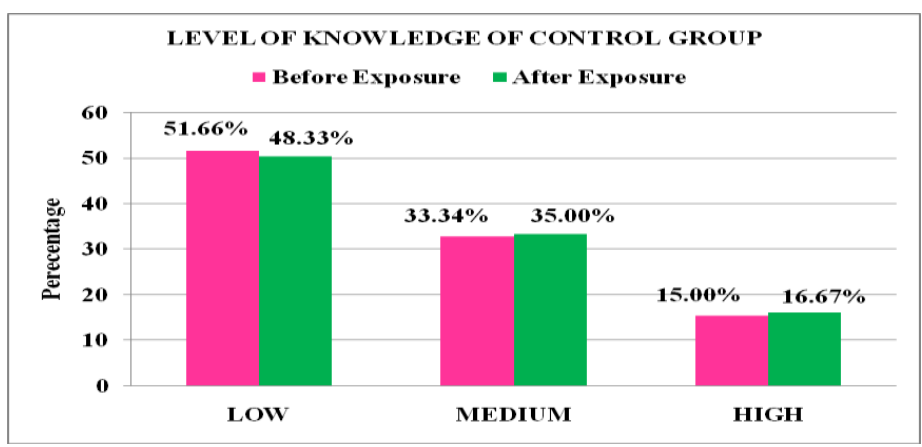

Fig.3 Difference in gain in knowledge of experimental and control group farmers after exposure to farm broadcast programme on rice production technology

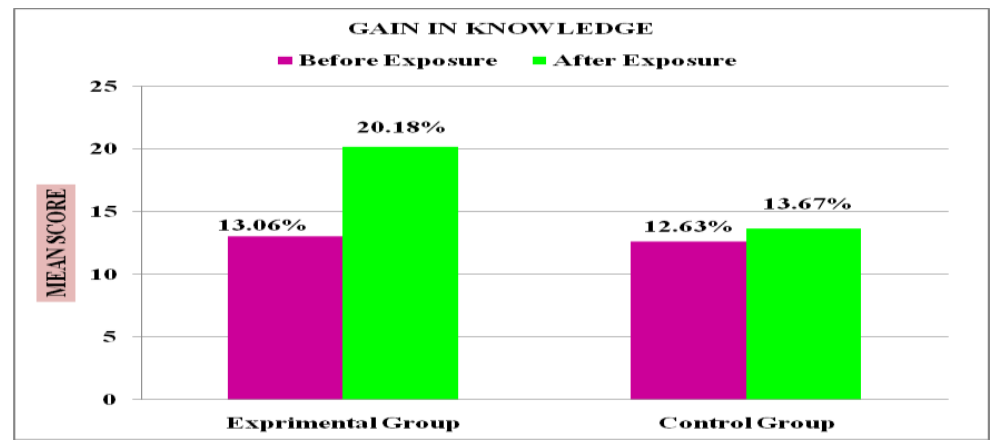

Mean Gain in Knowledge of Experimental and Control group Farmers on Rice Production Technology

It could be observed from the Table 3 . and Figure 3. that before exposure to farm broadcast programme on rice production technology, mean gain in knowledge scores of experimental group was 13.06 and the control group was 12.63. The mean knowledge scores immediately after exposure were 20.18 in experimental group and 13.67 in the control group. The gain in knowledge score was 7.12 in experimental group and 1.04 in control group. 
Null Hypothesis: There will be no significant difference between mean knowledge levels of televiewing farmers to farm broadcast programme on rice production technology before and after exposure.

Empirical Hypothesis: There will be significant difference between mean knowledge levels of televiewing farmers to farm broadcast programme on rice production technology before and after exposure.

As seen from the Table 3. that the computed ' $t$ ' value of experimental group found to be positive and significant at 0.01 level of probability with respect to gain in knowledge in rice production technology. Hence, the null hypothesis was rejected and the empirical hypothesis was accepted. So, it could be concluded that there was a positive and significant difference between knowledge levels before exposure and after exposure of farm broadcast programme viz., rice production technology. From the findings, it could be understood that experimental group farmers had scored 7.12 with regard to gain in knowledge when exposed to farm broadcast programme on rice production technology. This implied that the knowledge gained by the farmers with respect to rice production technology was substantial because of exposure to the intervening variable viz., farm broadcast programme. The possible reason might be farm broadcast programme is a powerful teaching technique having both audio and visual components, which will arouse the interest of the farmers and make them to pay full attention. And interesting way of presentation make to involve more number of senses of audience in understanding difficult concepts easily. From the results of the study, it was evident that farm broadcast programme is a powerful teaching technique for effective transfer of technology. Hence it is suggested that the extension personnel should make use of farm broadcast programmes in disseminating technologies and to improve the knowledge levels of the farmers.

It is also evident from Table 3. that, the computed ' $t$ ' value of control group also found to be positively significant at 0.01 per cent level of probability. It could be inferred that there is a significant difference between knowledge levels of farmers in control group before and after. This might be due to the testing effect created by pre-test, small sample size and other extraneous profile characteristics which were not included in the study. It could also be inferred from the results even though ' $t$ ' value found to be significant, mean knowledge score difference was too low viz., 1.04. That means only 1.04 per cent of farmers gained in knowledge on rice production technology. This might be due non-exposure of control group farmers to farm broadcast programme on rice production technology.

This findings were in conformity with the findings of Alexander (1963), Mishra et al., (1967), Knight and Singh (1975), Dey (1986), Singh and Verma (1987), Mrutyunjayam (1987), Kumari and Roy (1988), Cherian and Chandra (1989), Chandargi and Channa Gowda (1990), Decker and Merrill (1990), Alagar (1992), Jeyakumar and Manoharan (1999) and Kaiser Family Foundation (1999).

Mean Difference in the Scores of Knowledge of Farmers on Rice Production Technology

The ' $t$ ' test was applied to test the significant difference between experimental and control group farmers with regard to their knowledge on rice production technology and the results were presented in Table 4.

From the Table 4. it could be evident that the computed ' $t$ ' value was found to be positive 
and significant at 0.01 level of probability for mean gain in knowledge of experimental and control groups.

Hence, the null hypothesis was rejected and the empirical hypothesis was accepted. So it could be concluded that there was a positive and significant difference in the knowledge of farmers before and after exposure to rice production technology.

N.H.: There will be no significant difference in the mean knowledge levels of experimental and control group farmers before exposure and after exposure to farm broadcast programme on rice production technology.

E.H.: There will be significant difference in the mean knowledge levels of experimental and control group farmers before exposure and after exposure to farm broadcast programme on rice production technology.

It could be inferred from Table 4, that there was significant difference between experimental and control group farmers with regard to mean knowledge levels, before and after exposure to farm broadcast programme viz., rice production technology. The probable reason for the above trend may be due to both experimental and control groups had equal amount of knowledge on rice production technology before exposure to farm broadcast programme.

The result was in conformity with Alexander (1963), Mishra et al., (1967), Agarwal and Rao (1980), Chandrakandan (1982), Mrutyunjayam (1987), Singh and Verma (1987), Cherian and Chandra (1989).

\section{References}

Alagar, P. 1992. Study of the health communication and its impact on adult learning. M.Sc (Ag.) Thesis,
Bharathiyar University, Coimbatore, Tamil Nadu, India.

Alexander, F. D. 1963. Field experimental study in diffusion of knowledge of dairy cattle feeding through a TV school. Rural Sociology. 28 (2): 400404.

Chandargi, D. M and Channagowda, M. B. 1990. Extent of reach and influence of motion picture entitled, "Mixed Farming" on the knowledge of farmers - A field study. Mysore Journal of Agricultural Sciences. 24 (2): 528-535.

Chandrakandan, K. 1982. Effectiveness of farm broadcasts on listeners' affective, cognitive and psychomotor behaviours. Ph.D. Thesis. Tamil Nadu Agricultural University, Coimbatore, Tamil Nadu, India.

Cherian, A and Chandra, A. 1989. Impact of television on acquisition and retention of knowledge by rural people. Indian Journal of Extension Education. 25 (3\&4): 28-32.

Decker, D and Merril, W. 1990. Influencing practices through video tape: A systematic evaluation of communications technology. Journal of Extension. 28 (1): 28-30.

Dey, P. K. 1986. Relative effectiveness of radio and television on mass communication media in dissemination of agricultural information. M. Sc. (Ag.) Thesis. Indian Agricultural Research Institute, New Delhi, India.

Jeyakumar, K.A and Manoharan, M. 1999. Effectiveness of video education on sericulture enterprise among rural women. Journal of Extension Education. 10 (1): 2349-2350.

Kaiser Family Foundation, 1999. Crime most common story on local television news. Press Release. $28^{\text {th }}$ August, 2003.

Kaur, R. 1970. Impact of TV on farm women. 
M. Sc (Ag.) Thesis. Indian Agricultural Research Institute, New Delhi.

Knight, J. A. and Singh, K. N. 1975. Radio ownership among farm broadcast listeners. Madras Agricultural Journal. 68 (3): 846-848.

Kumari, P and Roy, S. 1988. Designing and testing effectiveness of flash cards for non-formal education of rural women. Indian Journal of Extension Education. 24 (3): 33.

Mishra, A and Sharma, S. K. 1967. Impact of television on farmers. All India Seminar Report on Extension Research. Indian Society of Extension Education. 3 (2): 248-254.

Mrutyunjayam, N. 1987. A critical analysis of farm telecast programme - An experimental study, $P h . \quad D$ Thesis. Acharya N. G. Ranga Agricultural University, Rajendranagar, Hyderabad, Andhra Pradesh, India.

Reddy, K. 2002. A critical analysis of Annadata Velugubata - Farm telecast programme in Andhra Pradesh. M. Sc. (Ag.) Thesis. Acharya N. G. Ranga Agricultural University, Rajendranagar, Hyderabad, Andhra Pradesh, India.

Sadamate, V. V and Sinha, B. P. 1974. Dissemination of farm information through TV, Radio and Block Extension Agency: A comparative study. Indian Journal of Extension Education. 12 (1): 6-9.

Shankaraiah, Ch and Singh, K.N. 1967. Predictive analysis of the factors related with knowledge of improved practices of vegetable cultivation. International Journal of Extension Education. 3 (1): 67-73.

Singh A. K. 1998. Tests, Measurement and Research Methods in Behavioural Science. Bharati Bhawan Publishers and Distributor, New Delhi.

Singh, P and Verma, T. 1987. Effectiveness of synchronized tape-cum- slide projector for imparting nutritional information to rural women. Indian Journal of Extension Education. 23 (2): 17-22.

TRAI, 2018. Review of general environment in the broadcasting and cable TV sector. Annual report, 201718.Telecome Regulatory Authority, New Delhi.pp.38-58.

Vikram, K. 2000. A study on Annadata Velugubata - A distance education programme in Chittoor district of Andhra Pradesh. M. Sc. (Ag.) Thesis. Acharya N. G. Ranga Agricultural University, Rajendranagar, Hyderabad, Andhra Pradesh, India.

www.barcindia.co.in

\section{How to cite this article:}

Krishnaji' M. V., T. Gopi Krishna and Deborah Messiana, N. 2021. Effect of Farm Broadcast Programmes on Gain in Knowledge of Farmers on Rice Production Technology in Andhra Pradesh. Int.J.Curr.Microbiol.App.Sci. 10(01): 777-785.

doi: https://doi.org/10.20546/ijcmas.2021.1001.095 